\title{
Analysis of Humid Air Turbine Cycle with Low- or Medium-Temperature Solar Energy
}

\author{
Hongbin Zhao, Pengxiu Yue, and Ling Cao \\ School of Mechatronics Engineering, China University of Petroleum, Beijing 102249, China \\ Correspondence should be addressed to Hongbin Zhao, hongbinzhaoyin@sina.com
}

Received 1 April 2009; Revised 5 July 2009; Accepted 28 July 2009

Recommended by Gopal Nath Tiwari

\begin{abstract}
A new humid air turbine cycle that uses low- or medium-temperature solar energy as assistant heat source was proposed for increasing the mass flow rate of humid air. Based on the combination of the first and second laws of thermodynamics, this paper described and compared the performances of the conventional and the solar HAT cycles. The effects of some parameters such as pressure ratio, turbine inlet temperature (TIT), and sollar collector efficiency on humidity, specific work, cycle's exergy efficiency, and solar energy to electricity efficiency were discussed in detail. Compared with the conventional HAT cycle, because of the increased humid air mass flow rate in the new system, the humidity and the specific work of the new system were increased. Meanwhile, the solar energy to electricity efficiency was greatly improved. Additionally, the exergy losses of components in the system under the given conditions were also studied and analyzed.
\end{abstract}

Copyright (๑) 2009 Hongbin Zhao et al. This is an open access article distributed under the Creative Commons Attribution License, which permits unrestricted use, distribution, and reproduction in any medium, provided the original work is properly cited.

\section{Introduction}

In recent years, the solar energy as a kind of clean and renewable energy is applied in many areas. More and more countries pay attentions to researching and developing solar energy and gradually extend the tremendous scale power generation. Solar thermal power plants can produce hightemperature heat that is converted into electricity by conventional power cycles $[1,2]$. The way of solar energy utilization by heating water into steam through solar collector for gas turbine has developed successfully in test and technology. Since 1970s, the solar thermal power generation technologies were emphasized in the major developed countries, such as the United States, Spain, Germany, and others. According to incomplete statistics, in recent 20 years, there are about 20 sets of solar power plants in the world, and the solar thermal power output is above $500 \mathrm{MW}$, and the biggest solar power is $80 \mathrm{MW}[3,4]$.

The HAT cycle is an advanced power generation system with relatively high efficiencies, low specific investment costs, high power, and low emissions. In the 1980s, the interest in gas turbine cycles with humidification towers was increased. The humid air turbine (HAT) was proposed by Y. Mori in 1983, and subsequently, the Japanese researchers applied patent in 1985 and RAO applied in 1989 [5, 6]. In the beginning of the 1990s, a research program on EvGT (evaporative gas turbine) was initiated in Sweden, and an advanced program of humid air turbine was studied in Japan $[7,8]$. Besides, HAT cycles combined with fuel cells have also been investigated. Rao and Samuelsen presented an HAT cycle integrated with a solid oxide fuel cell (SOFC) with a high thermal efficiency of $69.1 \%$. Up to now, many researchers have proposed the concepts of graded use of energy for improving the performance of HAT cycle [9-14].

In this paper, a new mode of HAT cycle that integrated with solar energy is proposed. In the new system, the solar collector will concentrate the solar energy for heating some circulating water in order to obtain high efficiency of solar energy utilization. Meanwhile, the main characteristics of the novel system will be disclosed. Additionally, we use the exergy analysis method to discuss and investigate some factors influencing on the performance of HAT cycle.

\section{Description of the New System}

In the proposed cycle system, solar energy is taken as an added heat resource for concentrating energy for the cycle. 
As shown in Figure 1, a solar collector (13) is arranged to absorb low- or medium-temperature solar energy for the additional circulating water in order to increase the water amount and temperature for the saturator (7). The ambient air enters the low-pressure compressor (1) and is compressed first, then it is cooled in intercooler (2) by circuiting water. After that, the compressed air goes into the high-pressure compressor (3) and is cooled for the second time in aftercooler (4). In the saturator, compressed air is humidified with hot water which passes through the saturator. The hot water quantity increases the mass flow and the specific heat of the working fluid which leads to additional power. The use of the recuperator (10) can recover the turbine (9) exhaust heat for the system. Then the humid air goes into the combustor (8) and is fired with natural gas. Thereafter, it inters the turbine (9) to do work and eventually is discharged into surroundings.

\section{Performances of the System to Study}

\subsection{Humidity $\mathrm{kg} \mathrm{kg}^{-1}$. Humidity is defined as}

$$
d=0.622 \frac{\varphi p_{\mathrm{s}}}{p-\varphi p_{\mathrm{s}}},
$$

where $\varphi$ means air relative humidity before entering the saturator. $p_{\mathrm{s}}$ denotes the steam pressure of the saturator. $p$ is the total pressure of wet air in saturator.

3.2. Specific Work $w_{n}$. In this paper, specific work and exergy efficiency as the main evaluated performance indeces are considered. They are illustrated in the following paragraphs.

Specific work is calculated as the actual net power output by per cycle working fluid and that can be presented as

$$
w_{\mathrm{n}}=\frac{W_{t}-W_{c}}{G_{0}},
$$

where $W_{t}=G_{9} c_{p, g} \eta_{t} T_{8}\left(1-\left(\pi_{t}\right)^{(k-1) / k}\right)$, kW. And $W_{\mathrm{cl}}=$ $G_{0} c_{p, a} T_{1}\left(\left(\pi_{1}\right)^{(k-1) / k}-1\right) / \eta_{c}$, here the $W_{\mathrm{cl}}$ is the work consumption of low-pressure compressor. For the work consumption of high-pressure compressor $W_{\mathrm{ch}}$, it is calculated as the low one. Here, $W_{c}=W_{\mathrm{cl}}+W_{\mathrm{ch}}, \mathrm{kW}$.

3.3. Exergy Efficiency of Cycle $\eta_{E, x}$. The exergy efficiency of the system is exhibited as follows:

$$
\eta_{E, x}=\frac{W_{t}-W_{c}}{F_{x \mathrm{CH}_{4}} \times E_{\mathrm{CH}_{4}}+E_{x, \text { solar }}},
$$

where $E_{\mathrm{CH}_{4}}$ is the standard chemistry exergy, $830.19 \mathrm{~kJ}$. $\mathrm{mol}^{-1}$, and $F_{x \mathrm{CH}_{4}}=G_{0} * f_{\mathrm{CH}_{4}}$, where $f_{\mathrm{CH}_{4}}$ is exhibited by (8) and (9).

3.4. Solar Energy to Electricity Efficiency ( $\left.\eta_{\text {solar }}\right)$. To investigate the contribution of the solar energy to the system, the solar energy contribution coefficient is calculated by the following equation:

$$
\delta=\frac{\left(W_{\text {solar }}-W_{0}\right)-\left(E_{x, \mathrm{CH}_{4}, \mathrm{solar}}-E_{x, \mathrm{CH}_{4}, 0}\right) \times \eta_{e, x}}{W_{\text {solar }}} .
$$

The solar energy to electricity efficiency is taken as an incremental efficiency, which is also defined as follows:

$$
\eta_{\text {solar }}=\frac{\left(W_{\text {solar }}-W_{0}\right)-\left(E_{x, \mathrm{CH}_{4} \text {,solar }}-E_{x, \mathrm{CH}_{4}, 0}\right) \times \eta_{e, x}}{E_{x, \text { solar }}} .
$$

\section{Model of the New System}

4.1. Assumption Conditions. In the calculation model of HAT cycle, to establish computation model for HAT cycle, the constraint conditions are needed to obtain the state parameters. In light of the experimental technology, more conditions that required are showed in Table 1. The air flow rate $\left(G_{0}\right)$ of the low-pressure compressor inlet is $50 \mathrm{~kg} / \mathrm{s}$, and the relative humidity is set to be $60 \%$. The environmental temperature is taken as $15^{\circ} \mathrm{C}$ and the surrounding pressure is taken as 1 bar. The exhaust temperature of the preheater is higher than emission acid temperature at least $10^{\circ} \mathrm{C}$. Water pump efficiency can be neglected for the whole system performance. Besides, other thermal conditions are also presented in Table 1.

4.2. Model of HAT Cycle. In this model, to calculate and determine the performance parameters of the cycle, a critical link is to build the exergy balances about every component. Each component comprises several equations for the calculation of each state point parameters, but only the exergy balance equations are listed as follows.

4.2.1. Compressor. The exergy balance equation can be expressed for

$$
G_{a} \times e_{x, a, \text { in }}+W_{c}=G_{a} \times e_{x, a, \text { out }}+I_{c} .
$$

4.2.2. Turbine. Currently, there is any unified and clear definition of turbine inlet temperature. Three kinds of definition methods about TIT are used commonly. The first definition is the combustor outlet temperature $\left(t_{A}\right)$. The second one is the gas temperature $\left(t_{B}\right)$ after the first stage nozzle in turbine. The third is that the average temperature $\left(t_{C}\right)$ of all gases which enters the turbine. Generally, the mentioned TIT is usually referred to the second one. In order to calculate conveniently, the first definition is selected in this paper. The exergy balance equation of the turbine is

$$
G_{8} \times e_{x, 8}=G_{9} \times e_{x, 9}+W_{t}+I_{t} .
$$

4.2.3. Combustor. The combustion process is nearly an isobaric process and complex. In order to calculate the consumption of fuel mass flow rate, chemical reaction is

$$
\begin{gathered}
\left(\frac{f_{\mathrm{CH}_{4}}}{16}\right) \mathrm{CH}_{4}+\frac{0.21}{29}\left(\mathrm{O}_{2}+3.76 \mathrm{~N}_{2}\right)+\left(\frac{d}{18}\right) \mathrm{H}_{2} \mathrm{O} \\
\longrightarrow\left(\frac{f_{\mathrm{CH}_{4}}}{16}\right) \mathrm{CO}_{2}+\left(\frac{f_{\mathrm{CH}_{4}}}{8}+\frac{d}{18}\right) \mathrm{H}_{2} \mathrm{O} \\
+\left(\frac{0.21}{29}-\frac{f_{\mathrm{CH}_{4}}}{8}\right) \mathrm{O}_{2}+0.02724 \mathrm{~N}_{2} .
\end{gathered}
$$




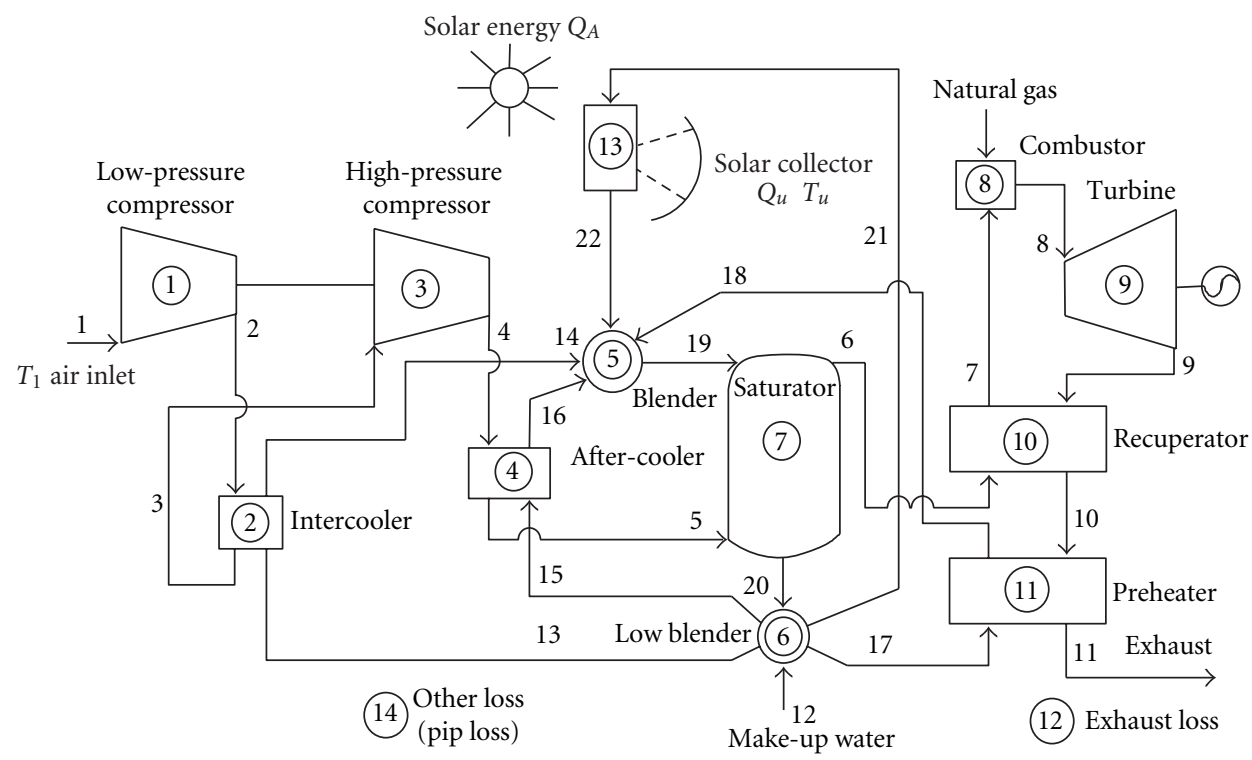

FIgure 1: The flow diagram of the HAT cycle with low- or medium-temperature solar energy.

Then, the corresponding energy balance equation is expressed as follows

$$
\begin{aligned}
& \frac{f_{\mathrm{CH}_{4}}}{16} \times Q_{m, \mathrm{LHV}} \times \eta_{r} \\
&=\left(\begin{array}{c}
\frac{f_{\mathrm{CH}_{4}}}{16} \Delta H_{m, \mathrm{CO}_{2}}+\left(\frac{f_{\mathrm{CH}_{4}}}{8}+\frac{d}{18}\right) \Delta H_{m, \mathrm{H}_{2} \mathrm{O}} \\
+\left(\frac{0.21}{29}-\frac{f_{\mathrm{CH}_{4}}}{8}\right) \Delta H_{m, \mathrm{O}_{2}}+\frac{0.79}{29} \Delta H_{m, \mathrm{~N}_{2}}
\end{array}\right)_{\text {products }} \\
&-\left(\begin{array}{c}
\frac{\mathrm{f}_{\mathrm{CH}_{4}}}{16} \Delta H_{m, \mathrm{CH}_{4}}+\frac{0.21}{29} \Delta H_{m, \mathrm{O}_{2}} \\
+\frac{0.79}{29} \Delta H_{m, \mathrm{~N}_{2}}+\frac{\mathrm{d}}{18} \Delta H_{m, \mathrm{H}_{2} \mathrm{O}}
\end{array}\right)_{\text {reactants }} .
\end{aligned}
$$

The mass flow rate of fuel consumption $\left(f_{\mathrm{CH}_{4}}, \mathrm{~kg} / \mathrm{s}\right.$ air $)$ can be calculated by the above equation.

The exergy balance equation is defined as

$$
G_{7} \times e_{x, 7}+F_{x \mathrm{CH}_{4}} \times E_{\mathrm{CH}_{4}}=G_{8} \times e_{8}+I_{c c} .
$$

4.2.4. Heat Exchanger. Exergy balance calculation of heat exchanger can be calculated by the following equation:

$$
\begin{aligned}
G_{w, \text { in }} & \times e_{x, w, \text { in }}+G_{a, \text { in }} \times e_{x, a, \text { in }} \\
& =G_{w, \text { out }} \times e_{x, w, \text { out }}+G_{a, \text { out }} \times e_{x, a, \text { out }}+I_{e} .
\end{aligned}
$$

4.2.5. Saturator. In the saturator, while the hot water transfers the heat and mass to the compressed air, the mass flow rate, temperature, and enthalpy of the humid air increase. In the outlet of saturator, the humid air is nearly saturated. The exergy balance equation is

$$
G_{19} \times e_{19}+G_{5} \times e_{x, 5}=G_{20} \times e_{x, 20}+G_{6} \times e_{x, 6}+I_{s} .
$$

4.2.6. Solar Collector. Some equations of solar collector are given as follows

$$
\begin{gathered}
Q_{U}=Q_{A}-Q_{L}, \\
E_{x, \text { solar }}=Q_{A} *\left(1-\frac{T_{0}}{T_{s c}}\right) .
\end{gathered}
$$

All gases such as the working fluid of air, combustion gases, and steam are supposed as actual gases, whose thermodynamic properties are influenced by pressure and temperature and with FORTRAN program for calculating thermodynamic parameters for different conditions. In addition, the solar collector temperature is assumed to be equal to the circulating water inlet temperature of the saturator.

\section{Thermodynamic Performance Analysis}

5.1. Analysis of the Performances of HAT Cycle. In this study, the main performances to research are humidity, specific work, exergy efficiency of the cycle, and the solar energy to electricity efficiency, including those of conventional (reference) and solar (proposed) HAT cycles. According to the parameters in different conditions, the rules of two cycles' performance parameters are studied, which varied with pressure ratio, turbine inlet temperature, and the solar collector efficiency. In this section, in order to reveal the variation laws of the performance, we choose a specific working condition as a typical calculating demonstration. The ratio of the collector circulating water mass flow rate with that of the internal water $(x)$ is 0.3 .

5.1.1. Variation of Humidity with Pressure Ratio. Figure 2 shows the variation of humidity with pressure ratio for solar collector efficiency of 0.65 at different turbine inlet temperatures (TITs). As the increase of the pressure ratio, the humidity is increased. The slope of the solar HAT is 
TABle 1: Assumption conditions.

\begin{tabular}{|c|c|c|}
\hline Item & Unit & Selected value \\
\hline Pressure ratio of compressor $(\pi)$ & - & $3 \sim 40$ \\
\hline Isentropic efficiency of compressor $\left(\eta_{c}\right)$ & - & 0.85 \\
\hline Relative internal efficiency of turbine & - & 0.88 \\
\hline Combustor efficiency $\left(\eta_{r}\right)$ & - & 0.99 \\
\hline Turbine inlet temperature (TIT) & ${ }^{\circ} \mathrm{C}$ & $1000 \sim 1200$ \\
\hline Pressure loss coefficient of compressor & $\%$ & 1 \\
\hline Pressure loss coefficient of after-cooler and intercooler & $\%$ & 3 \\
\hline Pressure loss coefficient of saturator & $\%$ & 2 \\
\hline Pressure loss coefficient of recuperator and preheater & $\%$ & 3 \\
\hline Pressure loss coefficient of combustor & $\%$ & 3 \\
\hline Minimum temperature difference between outlet humid air and inlet hot water of the saturator & ${ }^{\circ} \mathrm{C}$ & 5 \\
\hline The temperature difference between the outlet water and air wet bulb of saturator & ${ }^{\circ} \mathrm{C}$ & $3 \sim 10$ \\
\hline Make-up water temperature & ${ }^{\circ} \mathrm{C}$ & 15 \\
\hline Minimum heat transfer temperature difference between gas and water $\left(\Delta t_{1}\right)$ & ${ }^{\circ} \mathrm{C}$ & 10 \\
\hline Minimum heat transfer temperature difference between gas and gas $\left(\Delta t_{2}\right)$ & ${ }^{\circ} \mathrm{C}$ & 25 \\
\hline The inlet temperature of methane & ${ }^{\circ} \mathrm{C}$ & 25 \\
\hline Solar collector efficiency & - & $0.4 \sim 0.8$ \\
\hline Direct solar radiation & $\mathrm{kW} / \mathrm{m}^{2}$ & 900 \\
\hline The ratio of the collector circulating water mass flow rate with that of the internal water $(x)$ & - & 0.3 \\
\hline
\end{tabular}

greater than that of the conventional HAT. It can be seen from Figure 2 that the humidity is increased much higher for the solar HAT cycle than that of the conventional HAT, and with the pressure ratio increasing, the enhancement of humidity becomes great. For example, with TIT $=1100^{\circ} \mathrm{C}$, at the pressure ratio of 12 , the humidity is $12.44 \%$ and $17.35 \%$ for the conventional HAT and solar HAT, respectively, which is increased by 4.91 percent points, while with pressure ratio of 24 , it is $16.97 \%$ and $24.18 \%$ for the conventional HAT and solar HAT cycle, respectively, increasing by 7.21 percents points. In addition, the humidity changes almost the same value with the same TIT change. For instance, the humidity of the solar HAT is $19.51 \%, 20.00 \%$, and $20.6 \%$ for TIT at $1000^{\circ} \mathrm{C}, 1100^{\circ} \mathrm{C}$, and $1200^{\circ} \mathrm{C}$ with pressure ratio of 16 , respectively. Owing to the utilization of the solar energy that integrated with HAT cycle, the humidity improves.

5.1.2. Variation of Specific Work with Pressure Ratio. The Variation of specific work with pressure ratio for the cycle in different working conditions is demonstrated in Figure 3. The specific work is increased greatly with the increased temperature TIT and pressure ratio, but its slope is gradually going down with the enhancement of pressure ratio. In comparison with the conventional HAT cycle, the specific work is higher for the solar HAT cycle due to the increase of humidity which improves the mass flow rate of the steam in combustor. For example, with the pressure ratio of 8 and TIT of $1100^{\circ} \mathrm{C}$, the specific work is $366.2 \mathrm{~kJ} / \mathrm{kg}$ for the reference cycle and $398.6 \mathrm{~kJ} / \mathrm{kg}$ for the proposed cycle, increasing $32.4 \mathrm{~kJ} / \mathrm{kg}$. And with the increase of pressure ratio, the improvement of specific work increases more; for instance, at the pressure ratio of 20 and TIT of $1100^{\circ} \mathrm{C}$, the specific work is $519.9 \mathrm{~kJ} / \mathrm{kg}$ for the reference cycle and

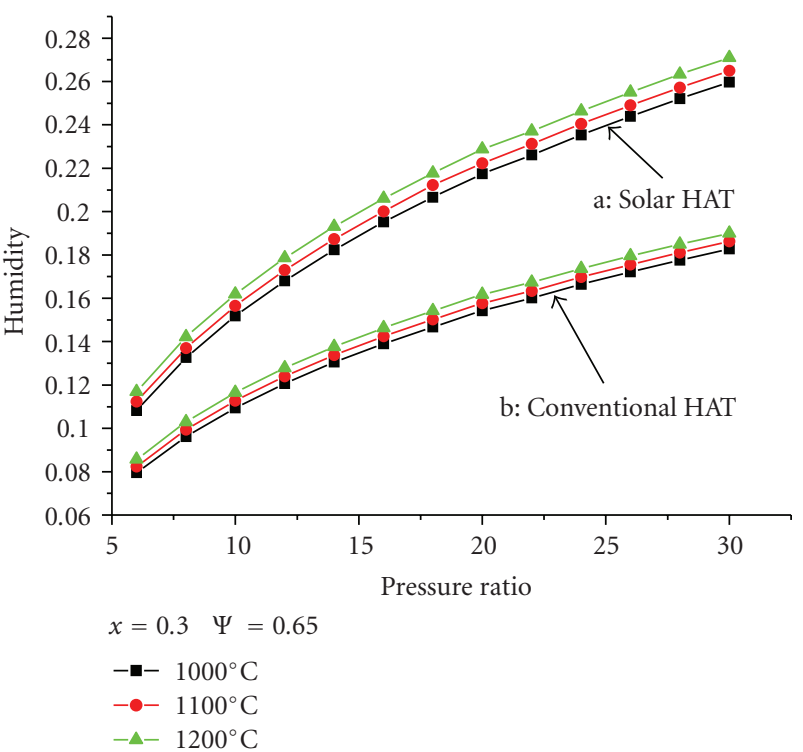

FIgURE 2: Variation of humidity with pressure ratio.

$604.7 \mathrm{~kJ} / \mathrm{kg}$ for the proposed cycle, improving $84.8 \mathrm{~kJ} / \mathrm{kg}$. In addition, the TIT has greater influence on the specific work. At the pressure ratio of 18 , when the TIT is changed from $1000^{\circ} \mathrm{C}$ to $1200^{\circ} \mathrm{C}$, the specific work is increased by $168.7 \mathrm{~kJ} / \mathrm{kg}$ for solar HAT cycle relative to the conventional HAT cycle.

5.1.3. Exergy Efficiency. Figure 4 depicts the effect of pressure ratio on exergy efficiency of the cycle at different turbine inlet temperatures. At the lower solar collector efficiency, 


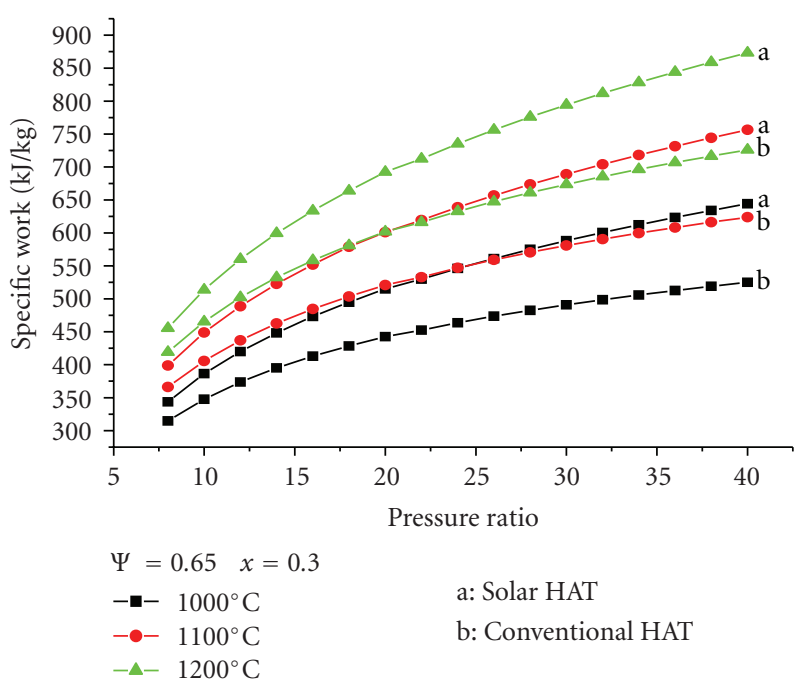

FIGURE 3: Variation of specific work with pressure ratio.

the cycle efficiency using solar energy is decreased. For instance, when the solar collector efficiency is 0.65 , at the pressure ratio of 12 , when the $\mathrm{TIT}$ is $1000^{\circ} \mathrm{C}, 1100^{\circ} \mathrm{C}$, and $1200^{\circ} \mathrm{C}$, the exergy efficiency of the conventional HAT cycle is $47.32 \%, 50.62 \%$, and $53.44 \%$, respectively, while that of the solar HAT cycle $46.02 \%, 49.10 \%$, and $51.84 \%$. For the exergy efficiency, the solar HAT cycle also has an optimum pressure ratio at different TITs similar to the conventional HAT cycle; however, with the solar energy utilization, the optimum pressure ratio will be little increased. For example, while the TIT is $1000^{\circ} \mathrm{C}$, the optimum pressure ratio is 8 for the reference cycle and 9 for the proposed cycle. The exergy efficiency is sensitive to TIT; for example, in the condition of $\pi=16$, when the TIT increases from $1100^{\circ} \mathrm{C}$ to $1200^{\circ} \mathrm{C}$, the efficiency improves from $48.95 \%$ to $51.75 \%$ for the proposed cycle. So the increase of TIT is a key factor to improve the performance of the HAT cycle.

5.1.4. The Solar Energy to Electricity Efficiency. The relationship between the solar energy to electric efficiency and the pressure ratio with different TIT is illustrated in Figure 5, assuming the solar collector efficiency of 0.62 . It can be seen that the solar energy to electricity efficiency increases obviously with the increase of pressure ratio at different TITs. However, it is affected little by the TIT.

In Figure 6, it illustrates the solar energy to electricity efficiency of the HAT cycle with solar energy versus the solar collector efficiency for different TITs and at a given pressure ratio of 16. As can be known that, the solar energy to electricity efficiency is enhanced linearly with the increase of solar collector efficiency. With the value of solar collector efficiency increasing 10 percent, the solar energy to electricity efficiency improves about 5 percent points.

Furthermore, we can compare the solar energy to electric efficiency in the solar HAT cycle with that in other advanced power cycles using solar energy, for example, the power cycle in which the solar energy is utilized for the methanol decomposition [12]. At the same conditions, such as the

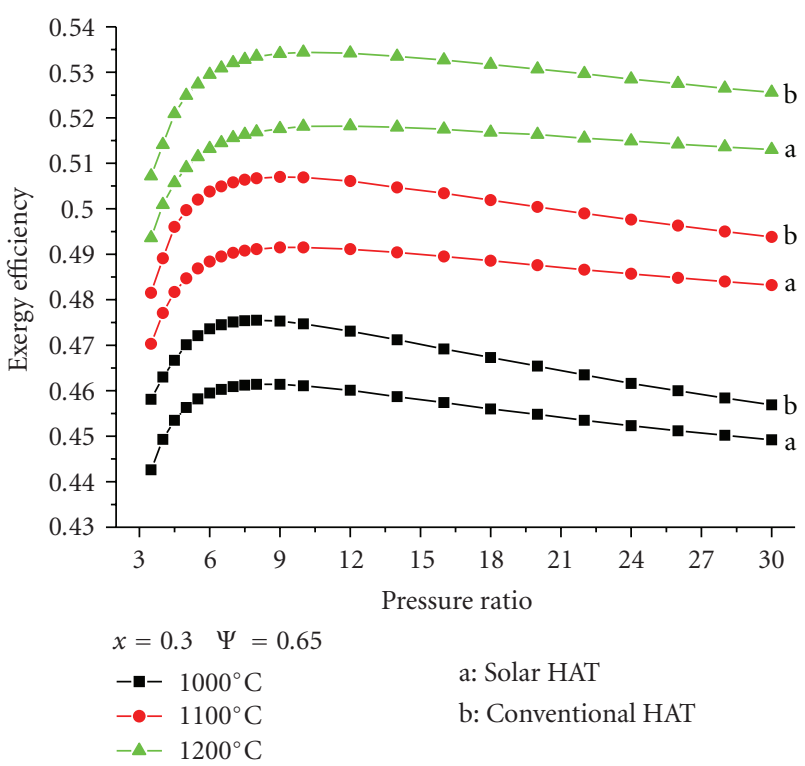

FIgURE 4: Exergy efficiency variation with pressure ratio.

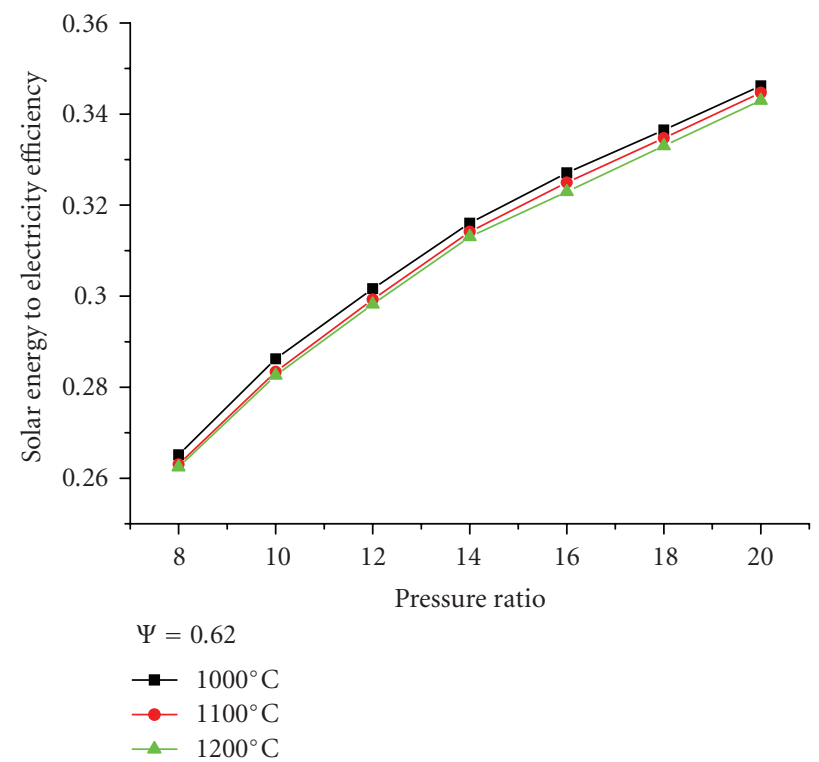

Figure 5: Solar energy to electricity efficiency variation with pressure ratio.

pressure ratio of 15 , TIT of $1200^{\circ} \mathrm{C}$, and solar collector efficiency of 0.62 , the solar energy to electricity efficiency in the solar HAT cycle is about $31.2 \%$, while that is about $30.6 \%$ for the power cycle of using solar energy for the methanol decomposition. Through comparison in other conditions, the solar energy to electricity efficiency in the solar HAT cycle is almost greater. According to the analysis, the solar energy to electricity is improved due to the solar energy integration with the HAT cycle.

5.2. Exergy Analysis of Components in the System. The most commonly used method for analysis of an energy-conversion 
TABLE 2: The data of every state point parameters for hat cycle with solar energy.

\begin{tabular}{|c|c|c|c|c|c|c|c|}
\hline Condition & & & $\pi=1$ & $=1100^{\circ} \mathrm{C}$, & & & \\
\hline Point & $\begin{array}{c}\text { Pressure } \\
(\mathrm{MPa})\end{array}$ & $\begin{array}{c}\text { Temperature } \\
\left({ }^{\circ} \mathrm{C}\right)\end{array}$ & $\begin{array}{c}\text { Flow rate } \\
(\mathrm{kg} / \mathrm{s})\end{array}$ & $\begin{array}{l}\text { Enthalpy } \\
\text { change } \\
(\mathrm{kJ} / \mathrm{kg})\end{array}$ & $\begin{array}{c}\text { Entropy } \\
\text { change } \\
(\mathrm{kJ} /(\mathrm{kg} \cdot \mathrm{K}))\end{array}$ & $\begin{array}{l}\text { Exergy } \\
(\mathrm{kJ} / \mathrm{kg})\end{array}$ & $\begin{array}{c}\text { Total exergy } \\
(\mathrm{kW})\end{array}$ \\
\hline 1 & 1.0132 & 15.0 & 50.32 & 0 & 0 & 0 & 0 \\
\hline 2 & 3.7537 & 170.2 & 50.32 & 158.10 & 0.0631 & 139.9 & 7040.32 \\
\hline 3 & 3.6411 & 65.0 & 50.32 & 50.42 & -0.2057 & 109.7 & 5519.06 \\
\hline 4 & 13.489 & 247.2 & 50.32 & 238.12 & -0.1382 & 278.0 & 13985.87 \\
\hline 5 & 13.0843 & 65.0 & 50.32 & 50.41 & -0.5742 & 215.9 & 10861.93 \\
\hline 6 & 12.8226 & 133.8 & 59.37 & 499.00 & 0.7318 & 288.1 & 17072.65 \\
\hline 7 & 12.438 & 560.6 & 59.37 & 1020.77 & 1.6225 & 553.2 & 32767.56 \\
\hline 8 & 12.0648 & 1100.0 & 60.36 & 1878.39 & 2.5475 & 1144.3 & 68793.08 \\
\hline 9 & 1.0769 & 585.6 & 60.36 & 1158.12 & 2.6379 & 398.0 & 23861.72 \\
\hline 10 & 1.0446 & 184.6 & 60.36 & 648.76 & 1.8436 & 117.5 & 6988.94 \\
\hline 11 & 1.0132 & 86.7 & 60.36 & 530.75 & 1.5629 & 80.4 & 4781.75 \\
\hline 12 & 13.0843 & 15.0 & 9.37 & 1.16 & -0.0002 & 1.2 & 11.26 \\
\hline 13 & 33.489 & 51.7 & 11.80 & 156.08 & 0.4992 & 12.2 & 144.34 \\
\hline 14 & 32.4843 & 160.2 & 11.80 & 615.06 & 1.7175 & 120.2 & 1418.32 \\
\hline 15 & 33.489 & 51.7 & 12.37 & 156.08 & 0.4992 & 12.2 & 151.32 \\
\hline 16 & 32.4843 & 228.3 & 12.37 & 919.33 & 2.3691 & 236.7 & 2928.97 \\
\hline 17 & 33.489 & 51.7 & 9.31 & 156.08 & 0.4992 & 12.2 & 112.36 \\
\hline 18 & 32.4843 & 228.3 & 9.31 & 919.33 & 2.3691 & 236.7 & 2174.86 \\
\hline 19 & 13.0843 & 204.7 & 43.54 & 810.54 & 2.1516 & 190.6 & 8258.80 \\
\hline 20 & 13.0843 & 62.7 & 34.17 & 200.53 & 0.64 & 16.1 & 548.17 \\
\hline 21 & 33.489 & 51.7 & 10.05 & 156.08 & 0.4992 & 12.2 & 122.41 \\
\hline 22 & 32.4843 & 204.7 & 10.05 & 811.28 & 2.1484 & 192.2 & 1922.43 \\
\hline
\end{tabular}

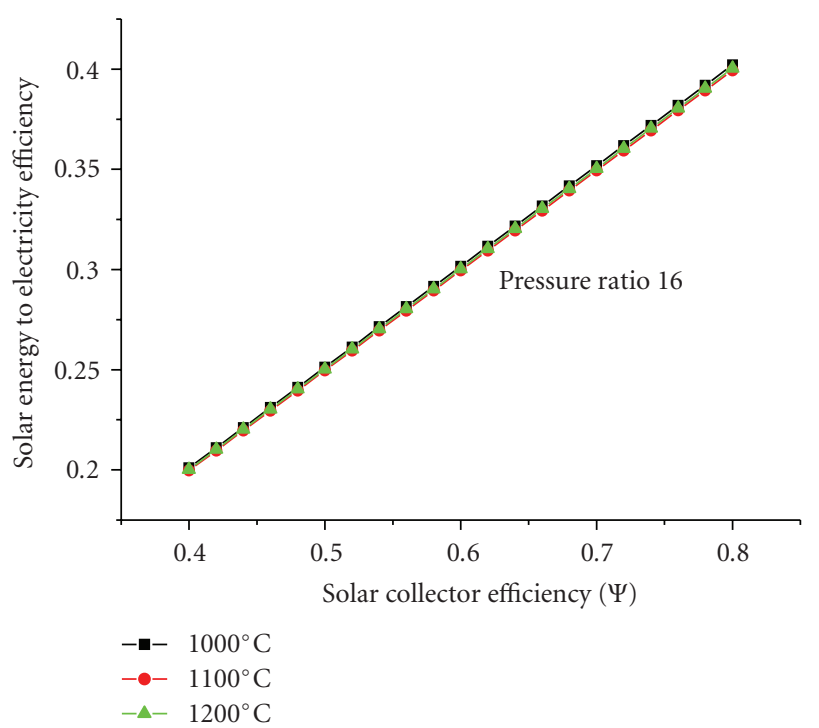

FIGURE 6: Solar energy to electricity efficiency variation with solar collector efficiency.

process is the first law of thermodynamics. However, there is increasing interest in the combined utilization of the first and second laws of thermodynamics, such as concepts as exergy efficiency and exergy destruction. The exergy analysis method is providing an indicator that points which direction efforts should be concentrated to improve the performance of the thermodynamic systems [15-17]. The exergy analysis method can find the useful work and the degree of energy utilization qualitatively and quantitatively. Therefore, it not only can estimate the efficiency of the system but also offer the target of improving equipment and saving energy by finding the weak links of the maximal exergy loss [17-20].

In order to obtain the utilization situation of the energy in system, the exergy analysis will be carried out in certain conditions of the system. Under the conditions of $\pi=14$, TIT $=1100^{\circ} \mathrm{C}$ and the ratio of solar collector circulating water mass flow rate with that of internal circulating water $(x=0.3)$, the thermal parameters of the solar HAT are shown in Table 2. In Table 3, it presents the exergy efficiency comparison, the exergy loss, as well as the exergy loss' percentage of every component in cycles. Additionally, Figure 7 shows the comparison of exergy loss about every component in the cycles.

We can see that the greatest exergy loss in the cycle occurs in the combustor because of chemical reaction that makes large temperature difference between the reactants and the combustion gases. The combustor exergy loss percentage is about $54.60 \%$ for the conventional HAT, and that is changed to $47.71 \%$ for solar HAT due mainly to the increase of 
TABLE 3: Exergy destruction and exergy efficiency of components.

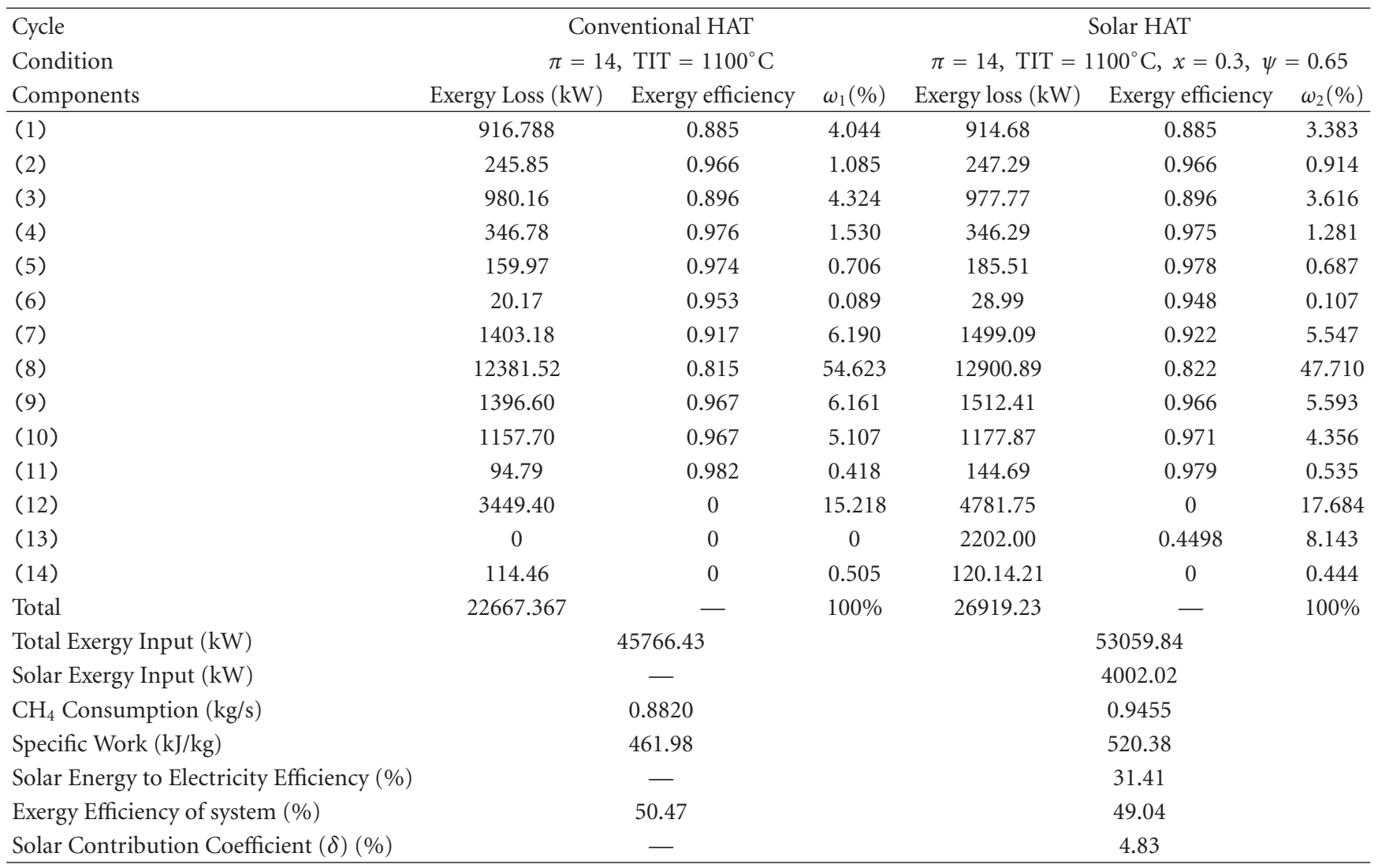

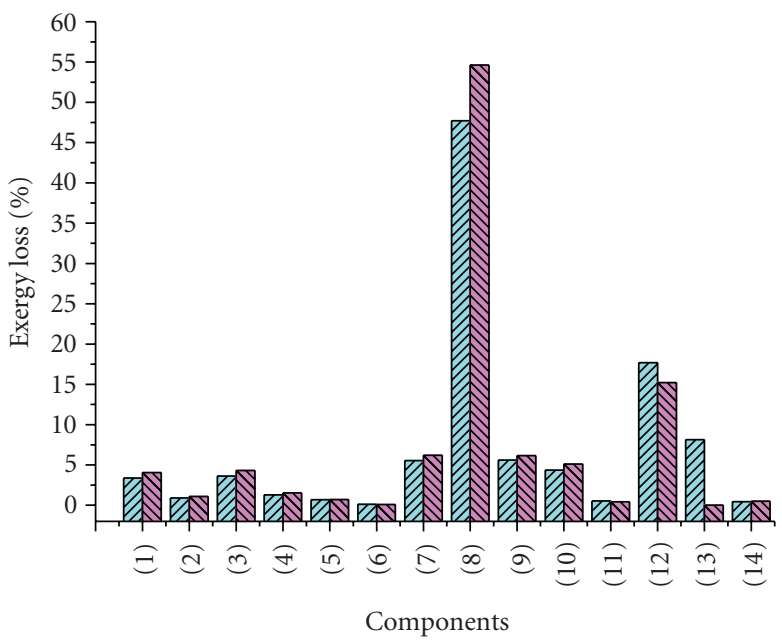

$\begin{array}{lll}\text { WIII Solar HAT } & \text { (5) Blender } & \text { (12) Exhaust loss } \\ \text { MIIV Conventional HAT } & \text { (6) Low blender } & \text { (13) Solar collector } \\ \text { (1) LPC } & \text { (7) Saturator } & \text { (14) Other loss } \\ \text { (2) Intercooler } & \text { (8) Combustor } & \\ \text { (3) HPC } & \text { (9) Turbine } & \\ \text { (4) After-cooler } & \text { (10) Recuperator } & \end{array}$

Figure 7: Exergy losses ratio of components in total exergy loss.

the gas flow rate and its exergy output. The exhaust loss, the regenerator, and the saturator all occupy a large proportion of exergy destruction. However, owing to the increase of steam in the exhaust gas carrying off a part of energy, the proportion of exhaust exergy loss in the solar HAT cycle is increased to $17.68 \%$ compared to the conventional HAT of $15.22 \%$. Also, the results reveal that the exergy loss in solar collector is about $8.14 \%$. For the two cycles, the exergy losses in turbine; the saturator and the recuperator all occupy nonnegligible parts. The exergy efficiency of the two cycles is about $50.47 \%$ and $49.04 \%$, respectively. Furthermore, the fuel mass flow rate consumption of the solar HAT is a little higher than the conventional HAT due to the additional circulating water which comes from the collector. On the contrary, the specific work is much greater. Moreover, the system of HAT cycle which uses solar energy improves the exergy efficiency in combustor and that provides helpful guidance for improving the design of the related components.

\section{Conclusions}

Mainly by using the exergy analysis method, this paper has studied the variation laws of the performance of the HAT cycle with solar energy as the assistant heat source. According to the obtained results from the thermodynamic analysis of the solar HAT and the conventional HAT, they show that some performance parameters increase greatly by utilizing the solar energy, such as humidity, the cycle's specific work, and the solar energy to electricity efficiency. Compared to 
the pure solar plants, this method is useful for improving the performance of the utilization efficiency of solar energy. In addition, the largest exergy loss of the components in cycle is combustor. In comparison with the conventional HAT, the exergy loss in combustor is decreased for solar HAT due to the steam flow rate increasing. It is also found that the exhaust gas, the exergy losses in saturator, recuperator, and turbine also occupy large proportion parts. Therefore, we can find out the weak link in energy utilization of the system. Through the analytical results, the utilization of solar energy combined with HAT cycle can provide an important direction for the future of the advanced power cycle using fossil fuels and renewable energy.

\section{Nomenclature and Subscripts}

\section{Nomenclature}

$C_{p}$

$d:$

Specific heat $(\mathrm{kJ} /(\mathrm{kg} \cdot \mathrm{K}))$

$E_{\mathrm{CH}_{4}}$ : The standard chemistry exergy of methane (kJ/kg)

$E_{x, \mathrm{CH}_{4}, \text { solar }}$ : Natural gas exergy with solar energy (kW)

$E_{x, \mathrm{CH}_{4}, 0}: \quad$ Natural gas exergy without solar energy $(\mathrm{kW})$

$E_{x, \text { solar }}: \quad$ Exergy of solar energy $(\mathrm{kW})$

$e_{x}: \quad$ Exergy $(\mathrm{kJ} / \mathrm{kg})$

$f_{\mathrm{CH}_{4}}$ : Consumption of natural gas mass flow $(\mathrm{kg} / \mathrm{s}$ air)

$F_{x \mathrm{CH}_{4}}$ : Consumption of natural gas mass flow $(\mathrm{kg} / \mathrm{s})$

$G$ : $\quad$ Working fluid flow $(\mathrm{kg} / \mathrm{s})$

$G_{0}$ : $\quad$ Air mass flow of the low-pressure compressor inlet $(\mathrm{kg} / \mathrm{s})$

I: $\quad$ Exergy loss $(\mathrm{kW})$

$p: \quad$ The total pressure of saturated wet air in saturator

$p_{s}: \quad$ The steam pressure of the saturator

$Q_{U}: \quad$ Energy output of solar collector $(\mathrm{kW})$

$Q_{A}$ : The collector absorption of solar energy $(\mathrm{kW})$

$Q_{L}: \quad$ The solar energy dissipate for surroundings $(\mathrm{kW})$

$Q_{m, \mathrm{LHV}}: \quad$ Lower heating value of methane $(\mathrm{kJ} / \mathrm{kmol})$

$T_{0}$ : $\quad$ Surrounding temperature $(\mathrm{K})$

$T_{s c}: \quad$ Solar collector temperature $(\mathrm{K})$

$W_{t}$ : $\quad$ Work output by turbine $(\mathrm{kW})$

$W_{c}$ : $\quad$ Work input by compressor $(\mathrm{kW})$

$w_{t}: \quad$ Specific work of turbine $(\mathrm{kJ} / \mathrm{kg})$

$w_{n}: \quad$ Specific work of cycle $(\mathrm{kJ} / \mathrm{kg})$

$W_{\text {solar }}$ : Net power with solar energy

$W_{0}$ : $\quad$ Net power without solar energy

$x$ : $\quad$ The ratio of the collector circulating water mass flow rate with that of the internal water

$\Delta H_{m, x}: \quad$ Enthalpy of products and reactants in combustor $(\mathrm{kJ} / \mathrm{kmol})$

$\varphi$ : $\quad$ The relative humidity of air before entering the saturator

$\psi$ : $\quad$ Solar collector efficiency
K: $\quad$ Adiabatic exponent

$\eta_{E, x}:$ Exergy efficiency of solar HAT cycle

$\eta_{e, x}$ : Exergy efficiency of conventional HAT cycle

$\eta_{\text {solar }}$ : Solar energy to electricity efficiency

$\eta_{r}: \quad$ Combustor efficiency

$\delta$ : $\quad$ Solar contribution coefficient

$\pi_{t}$ : Expansion pressure ratio of turbine

$\omega_{1}$ : Percentage of the exergy loss of every component to total exergy loss in reference HAT cycle

$\omega_{2}$ : Percentage of the exergy loss in every component to the total exergy loss of solar HAT cycle.

\section{Subscripts}

$\begin{array}{ll}\text { a: } & \text { Air } \\ \text { w: Water } \\ \text { in: Inlet } \\ \text { out: } \text { Outlet } \\ \text { g: Gas } \\ \text { c: Compressor } \\ \text { t: } & \text { Turbine } \\ \text { e: } & \text { Heat exchanger } \\ \text { cc: } & \text { Combustor } \\ \text { s: } & \text { Saturator } \\ \text { sc: } & \text { Solar collector. }\end{array}$

\section{Acknowledgment}

The authors are profoundly grateful for the educational fund by the China University of Petroleum, Beijing.

\section{References}

[1] Y. Wang, Y. Liu, and W. Tian, "Research progress on hybrid PV/thermal solar system," Solar Energy Journal, vol. 26, no. 5, pp. 639-646, 2005.

[2] D. Zeng, "Technology progress in solar thermal power generation," Journal of Gansu Sciences, vol. 8, no. 3, pp. 54-60, 1996.

[3] M.-L. Yang, X.-X. Yang, R.-M. Lin, and J.-L. Yuan, "Solar energy-based thermal power generation technologies and their systems," Thermal Energy Power Engineering, vol. 23, no. 3, pp. 221-228, 2008.

[4] J. Yuan, Integration research on a novel system of solar energy heat utilization, M.S. thesis, Graduate University of Chinese Academy of Sciences, 2007.

[5] S. Jiao, "Thermodynamic analysis for humid air turbine cycle," Gas Turbine Technology, vol. 8, no. 2, pp. 1-11, 1995.

[6] L. Wang and H. Song, "Development and status of humid air turbine cycle," Energy Saving and Environment Protection, no. 8, pp. 26-29, 2004.

[7] M. Jonsson and J. Yan, "Humidified gas turbines-a review of proposed and implemented cycles," Energy, vol. 30, no. 7, pp. 1013-1078, 2005.

[8] P. Schwarzbözl, R. Buck, C. Sugarmen, et al., "Solar gas turbine systems: design, cost and perspectives," Solar Energy, vol. 80, no. 10, pp. 1231-1240, 2006.

[9] R. Lin, H. Jin, and R. Cai, "Total energy systems and energy cascade utilization principle of gas turbines," Gas Turbine Technology, vol. 21, no. 1, pp. 1-12, 2008. 
[10] Z. Xu, A study on air humidification process of humid air turbine cycle, Doctoral thesis, Graduate University of Chinese Academy of Sciences, 2006.

[11] W. Li, Design of cooperative control and simulation for an independent solar fuel cell hybrid power system, Doctoral thesis, Shanghai Jiao Tong University, 2007.

[12] H. Hong, H. Jin, J. Ji, Z. Wang, and R. Cai, "Solar thermal power cycle with integration of methanol decomposition and middle-temperature solar thermal energy," Solar Energy, vol. 78, no. 1, pp. 49-58, 2005.

[13] D. Y. Goswami and F. Xu, "Analysis of a new thermodynamic cycle for combined power and cooling using low and mid temperature solar collectors," Journal of Solar Energy Engineering, vol. 121, no. 2, pp. 91-97, 1999.

[14] X. R. Zhang, H. Yamaguchi, D. Uneno, K. Fujima, M. Enomoto, and N. Sawada, "Analysis of a novel solar energypowered Rankine cycle for combined power and heat generation using supercritical carbon dioxide," Renewable Energy, vol. 31, no. 12, pp. 1839-1854, 2006.

[15] H. Jin, H. Zhao, Z. Liu, and R. Cai, "A novel EFHAT system and exergy analysis with energy utilization diagram," Energy, vol. 29, no. 12-15, pp. 1983-1991, 2004.

[16] A. Hepbasli, "A key review on exergetic analysis and assessment of renewable energy resources for a sustainable future," Renewable and Sustainable Energy Reviews, vol. 12, no. 3, pp. 593-661, 2008.

[17] D. Hirsch, M. Epstein, and A. Steinfeld, "The solar thermal decarbonization of natural gas," International Journal of Hydrogen Energy, vol. 26, no. 10, pp. 1023-1033, 2001.

[18] H. Taniguchi, K. Mouri, T. Nakahara, and N. Arai, "Exergy analysis on combustion and energy conversion processes," Energy, vol. 30, no. 2-4, pp. 111-117, 2005.

[19] A. Vidal, R. Best, R. Rivero, and J. Cervantes, "Analysis of a combined power and refrigeration cycle by the exergy method," Energy, vol. 31, no. 15, pp. 3401-3414, 2006.

[20] X. D. Wang and L. Zhao, "Analysis of zeotropic mixtures used in low-temperature solar rankine cycles for power generation," Solar Energy, vol. 83, no. 5, pp. 605-613, 2009. 


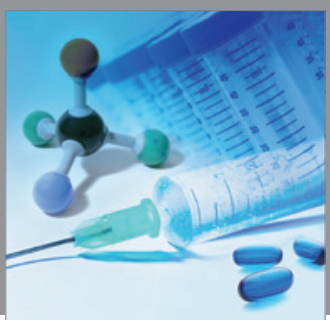

International Journal of

Medicinal Chemistry

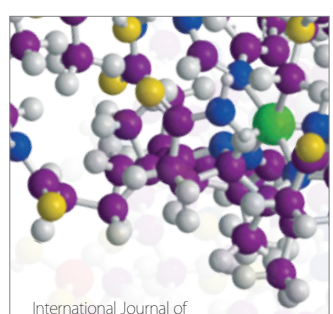

Carbohydrate Chemistry

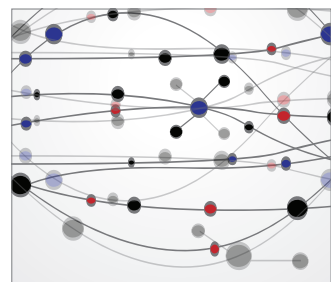

The Scientific World Journal
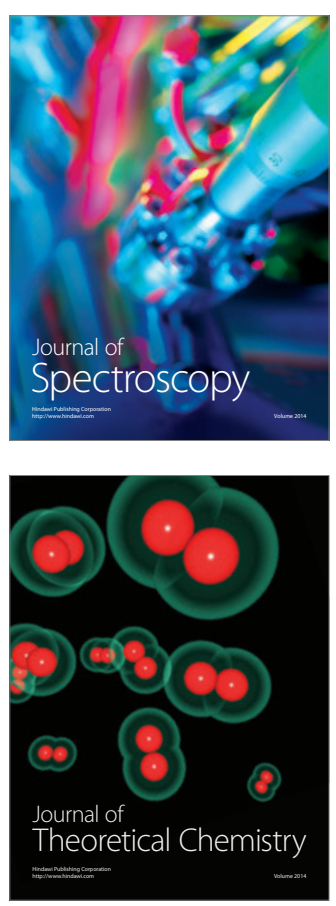
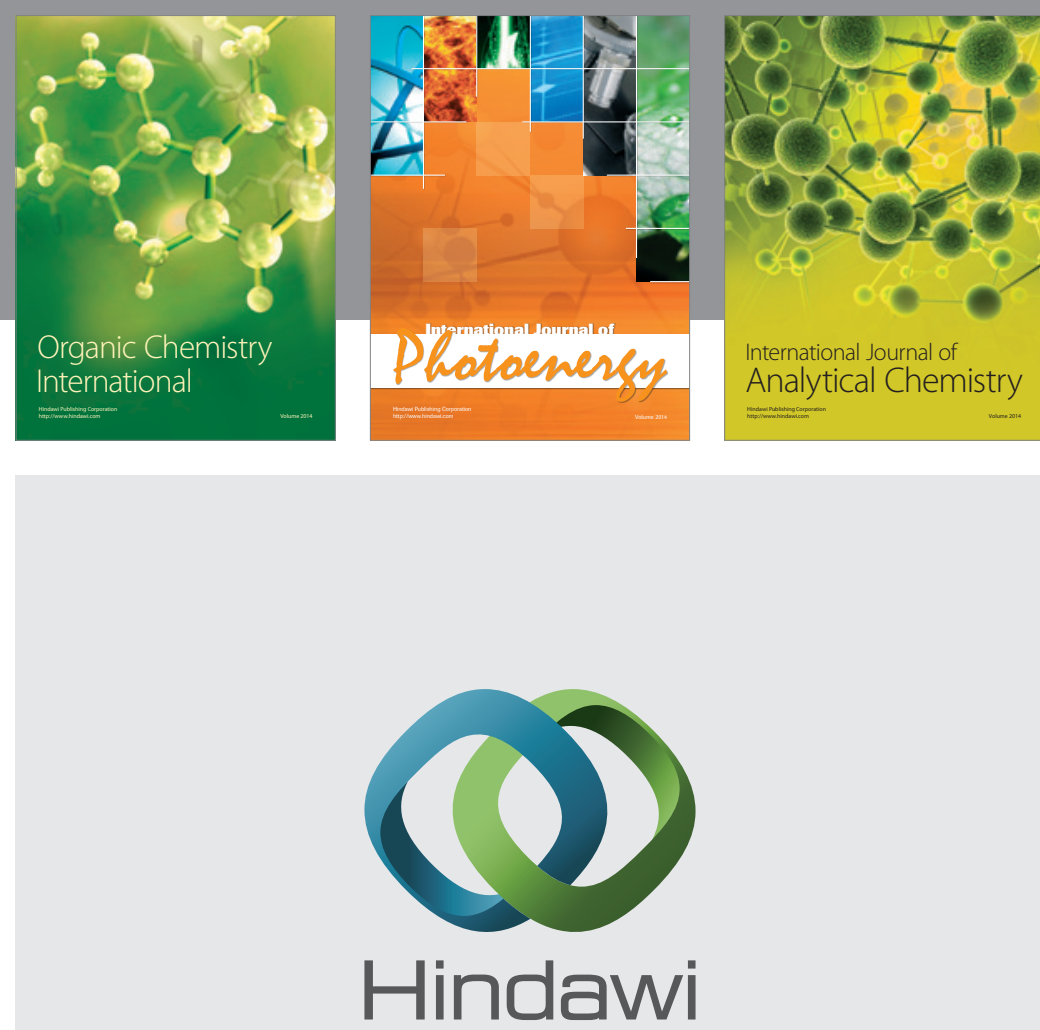

Submit your manuscripts at

http://www.hindawi.com
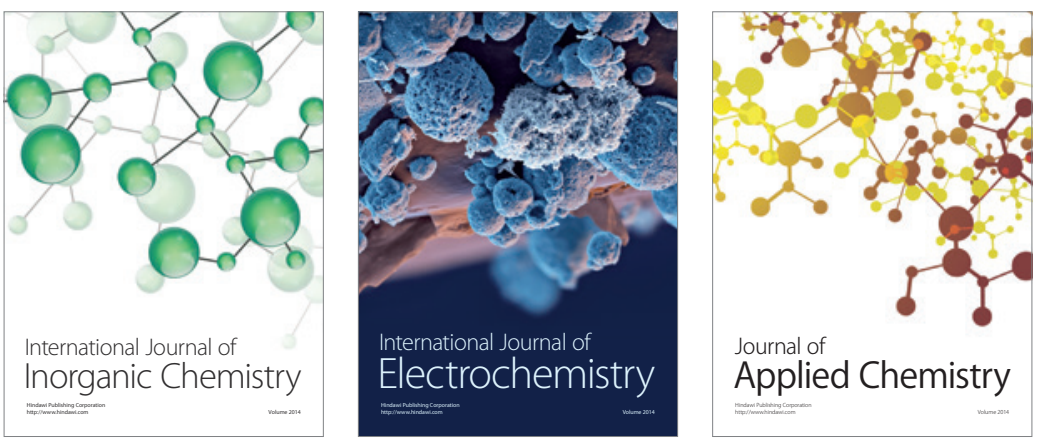

Journal of

Applied Chemistry
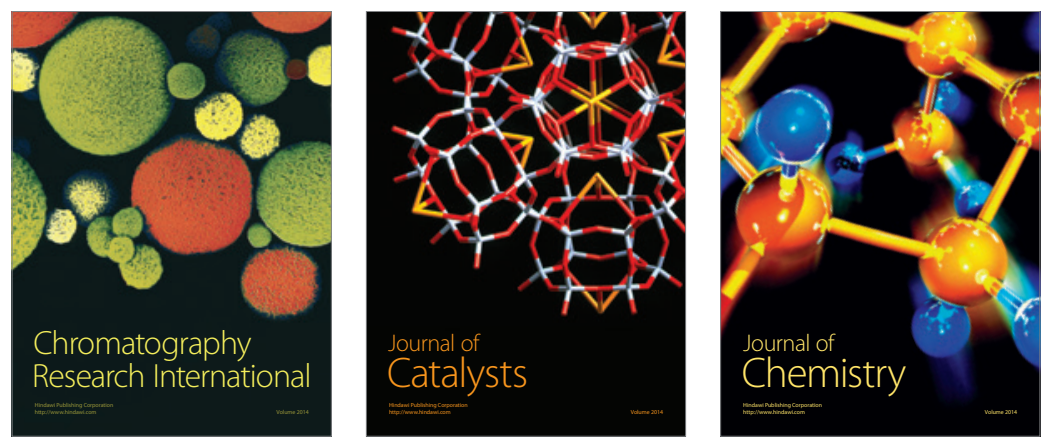
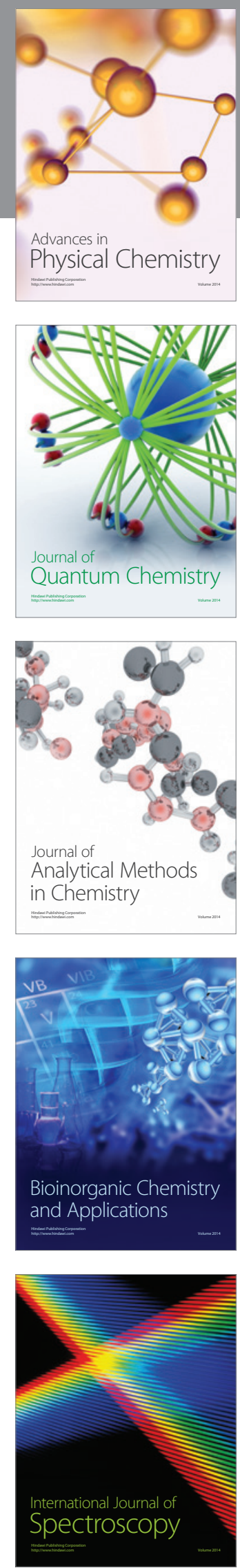